\title{
TERRIBLE TRIAD OF THE ELBOW: EVALUATION OF SURGICAL TREATMENT
}

Leandro Cardoso Gomide', Dagoberto de Oliveira Campos², José Maria Ribeiro de Sá ${ }^{1}$, Marcelo Rangel Pamfílio de Sousa ${ }^{1}$, Thiago Correa do Carmo ${ }^{3}$, Fernando Brandão Andrada ${ }^{4}$

\section{ABSTRACT}

Objectives: To evaluate the epidemiology of and surgical results from treating elbow fracture-dislocations, including only the cases in which dislocation is associated with fracture of the coronoid process and the radial head (terrible triad). Methods: Nineteen patients were evaluated: 12 males and 7 females. The medical records were analyzed to gather data about the mechanism of injury, fracture pattern, time elapsed until surgery and type of procedure applied. A clinical assessment was made to measure elbow range of motion, and the MEPS questionnaire was applied. Results: The most common mechanism of injury in our sample was a fall from a height (12 patients). All the patients underwent surgical treatment and the mean time elapsed between the date of the injury and the surgery was 16.1 days. The mean follow-up was 50.3 months. The mean range of flexion-extension obtained was $112^{\circ}$ and the mean range of pronation-supination obtained was $127.9^{\circ}$. The mean score from the MEPS questionnaire was 86 points, and excellent and good results were obtained for 15 patients $(79 \%)$. The time elapsed until surgery, final flexion-extension range greater than $100^{\circ}$ and flexion contracture of less than $30^{\circ}$ were shown to have a statistically significant relationship with a good final clinical result. Five patients had complications, of which three cases related to peripheral nerves, one case to pseudarthrosis and one case to recurrent instability. Conclusions: Despite the severity of the injuries found in the terrible triad of the elbow, most of the patients evaluated here achieved elbow stability with good clinical results. The factors that led to better clinical results were surgery not more than 14 days after the injury, flexion-extension range greater than $100^{\circ}$ and flexion contracture less than $30^{\circ}$.

Keywords - Dislocations; Elbow Joint; Radius Fractures

\section{INTRODUCTION}

The elbow is one of the most stable joints in the skeleton, but when one or more parts of its architecture are injured in the presence of dislocation, the risk of recurrent instability or arthrosis becomes high ${ }^{(1)}$. The term "terrible triad" is used to describe dislocation of the elbow associated with fracturing of the radius and the coronoid process. This name is used because of the resulting instability from this injury, which leads to difficulty in managing such cases, even among experienced surgeons ${ }^{(2,3)}$.
The terrible triad commonly occurs in young patients. Among its complications are limitation of the range of motion, persistent instability, delayed consolidation, pseudarthrosis and proximal radioulnar synostosis. The results from conservative treatment are generally poor and evolve to arthrosis, recurrent instability or great stiffness of the elbow due to prolonged immobilization $^{(1,4)}$. Although the elbow is the second most frequently dislocated joint in the body, this injury pattern is very uncommon and little information on its treatment has been published in the literature ${ }^{(2)}$.

1 - Attending Physician in the Upper Limb Group, Hospital das Clínicas, Federal University of Uberlândia, MG, Brazil.

2 - Head of the Upper Limb Group, Hospital das Clínicas, Federal University of Uberlândia, MG, Brazil.

3 - Resident in the Upper Limb Group, Hospital das Clínicas, Federal University of Uberlândia, MG, Brazil.

4 - Third-year Resident in Orthopedics, Hospital das Clínicas, Federal University of Uberlândia, MG, Brazil.

Work performed by the Upper Limb Group, Federal University of Uberlândia, MG, Brazil.

Correspondence: Avenida Pará, 1.720 (Sala da Ortopedia), Bairro Umuarama - 38400-000 - Uberlândia, MG - E-mail: leandro@orthomedcenter.com.br

Work received for publication: October 01, 2010; accepted for publication: March 22, 2011.

The authors declare that there was no conflict of interest in conducting this work 
The present study had the aim of reviewing cases of elbow fracture-dislocation that fit within the spectrum of the terrible triad. An analysis on its epidemiology, the treatment methods used and the clinical and radiographic results was made.

\section{SAMPLE AND METHOD}

After investigating in the nosology sector of the teaching hospital (Hospital de Clínicas) of the Federal University of Uberlândia, MG, we found records relating to 35 skeletally mature patients with a diagnosis of elbow dislocation in association with fracturing of the coronoid process and head of the radius (Figure 1). These patients underwent surgical treatment between January 1999 and January 2008, with as minimum postoperative follow-up of two years. Out of this total, 14 patients could not be located to make a new clinical assessment, one patient had died and one patient was excluded from the group because the presentation was elbow dislocation plus Monteggia fracture. In this manner, 19 patients remained in the group.

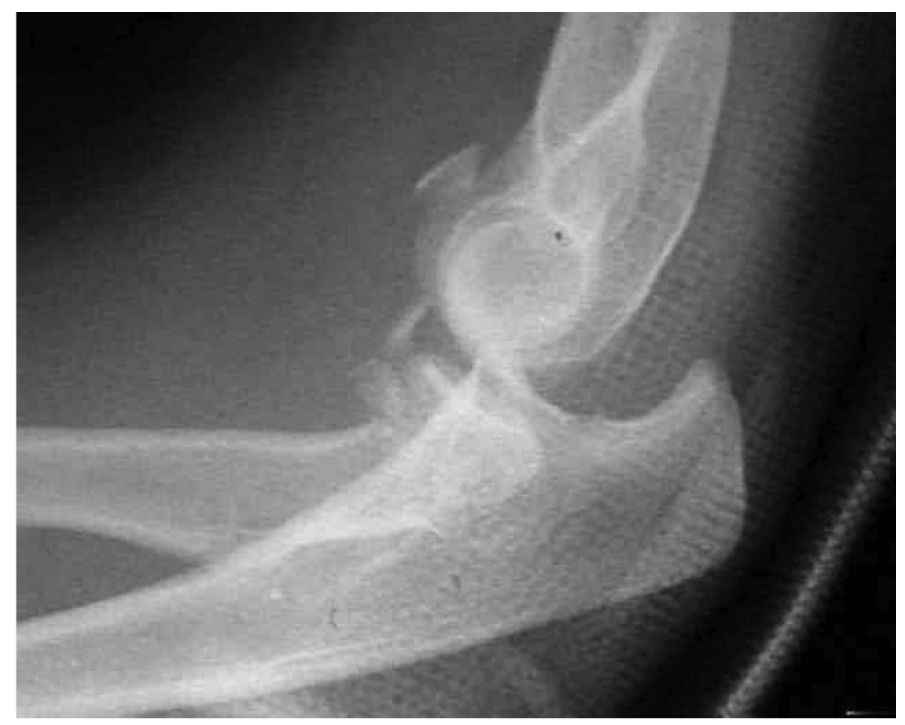

Figure 1 - Lateral-view radiograph of elbow, demonstrating "terrible triad".

Thus, a retrospective analysis on the medical files was made, to gather data relating to sex, age, trauma mechanism, classification of the radial fracture according to Mason $^{(5)}$, classification of the coronoid process according to Regan and Morrey ${ }^{(6)}$, side affected (dominant or non-dominant), time taken to perform surgery, treatments administered to the radial head and coronoid process, and complications presented. As done by Lindenhovius et $\mathrm{al}^{(7)}$, we took acute treatment to mean surgery that was done within 14 days of the injury.

The patients in this study were always operated by two surgeons out of a group of five orthopedists who were all members of the upper-limb service of the Federal University of Uberlândia. The surgical technique used began with lateral entry (Kocher) to access the head of the radius and perform the treatment most indicated for this type of fracture, i.e. excision of the fragment provided that its absence would not harm the stability, or if this was impossible, fixation of the fragment; osteosynthesis when possible; and arthroplasty, in comminuted fractures without the possibility of fixation. Following this, we assessed the stability of the elbows in which we found type 1 coronoid fractures. If these were stable, we simply sutured the lateral ligament complex using non-absorbable sutures with anchors or with transosseous sutures. If they were unstable, we then performed fixation on the fractures. In cases of type 2 or type 3 coronoid fractures, we performed fixation routinely on this structure, through the same lateral incision in cases that required excision of the head of the radius, or otherwise through a medial access. If the instability persisted, the medial soft tissues were reconstructed, also using non-absorbable sutures with anchors. The patients were immobilized for two weeks after the operation, using a brace from the axilla to the palm with the elbow at 90 degrees of flexion and neutral pronosupination. After this, all the patients were sent for physiotherapy.

\section{ASSESSMENT}

The patients were evaluated clinically by means of MEPS (Mayo Elbow Performance Score) ${ }^{(8)}$, which quantifies pain, mobility, stability and function, classifying the results through a scoring system in which 90 to 100 points is considered excellent; 75 to 89 , good: 60 to 74 , fair; and less than 60 , poor. In addition, goniometry was used to measure the flexion, extension, pronation and supination of the affected limb. In the imaging assessment, radiographs were produced in anteroposterior and lateral views on the operated elbow. 
A statistical assessment was made by applying Student's t test, taking the significance level as $\mathrm{p}<$ 0.05 . The parameters evaluated were the type of fracture, side affected, range of motion, time elapsed until surgery and clinical result obtained according to MEPS.

\section{RESULTS}

The majority of the patients were male (twelve men and seven women) and the mean age was 48 years (range: 19 -70). Regarding the side affected, the fracture was on the dominant side in eleven patients and in the non-dominant side in eight patients. The trauma mechanisms most commonly encountered were, respectively, falls from a height, motor (Box 1).

Box 1 - Epidemiological data.

\begin{tabular}{|c|c|}
\hline Gender & 12 \\
\hline Male & 7 \\
\hline Female & $11(58 \%)$ \\
\hline Mean age & $48.0(19-70)$ years \\
\hline Mean follow-up & $50.3(25-108)$ months \\
\hline Mean time elapsed until surgery & $16.1(1-60)$ days \\
\hline Trauma mechanism & \\
\hline Fall from height & $12(63 \%)$ \\
\hline Motorcycle accident & $3(15 \%)$ \\
\hline Bicycle accident & $2(11 \%)$ \\
\hline Fall from own height & $2(11 \%)$ \\
\hline Fracture of radial head & \\
\hline Mason 1 & $8(42 \%)$ \\
\hline Mason 2 & $11(58 \%)$ \\
\hline Mason 3 & \\
\hline Fracture of coronoid process & $11(58 \%)$ \\
\hline Reagan and Morrey 1 & $6(31 \%)$ \\
\hline Reagan and Morrey 2 & $2(11 \%)$ \\
\hline Reagan and Morrey 3 & \\
\hline
\end{tabular}

In the initial radiographic assessment, most of the fractures of the head of the radius were of type 3 (58\%) and type $2(42 \%)$, according to Mason's classification, while no fractures of type 1 were found. Regarding fractures of the coronoid process, most of the fractures were of type 1 (58\%), while six (31\%) were type 2 and two (11\%) were type 3, according to the classification of Regan and Morrey. The mean length of follow-up was 50.3 months, with a range from 25 to 108 months, and the mean time elapsed between the accident and performing the surgery was 16.1 days (range: $1-60$ ). The fractures of the head of the radius were treated using a metal prosthesis for the head of the radius in 10 patients (Figures 2, 3, 4 and 5). In another seven patients, open reduction and internal fixation was performed (screw with or without a plate). For the remaining two patients, the fractured fragment was resected. In treating the coronoid process, nine patients were treated without fixation of the fragment, and the other nine patients underwent suturing alone or in association with another fixation method (anchor or screw). In one patient, a plate was placed on the ulna because of the extent of the fracture (Box 2). In the final radiographic evaluation, we found that ten patients had evolved with calcifications surrounding the elbow. Clinically, the patients were evaluated using the final range of motion (flexion/extension and pronation/supination) and MEPS (Box 3). The final flexion/extension was $112^{\circ} \pm 28^{\circ}$, the mean contracture in flexion was $24.3^{\circ} \pm 20^{\circ}$ and the mean flexion

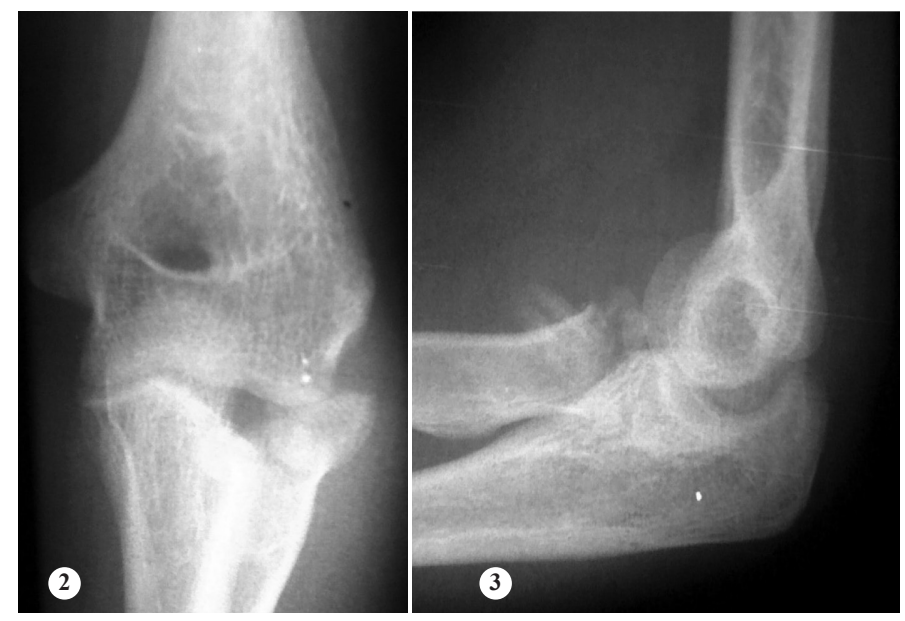

Figures 2 and 3 - Radiographs demonstrating fractures of the head of the radius and coronoid, and subluxated elbow, after reduction of a terrible triad of the elbow.

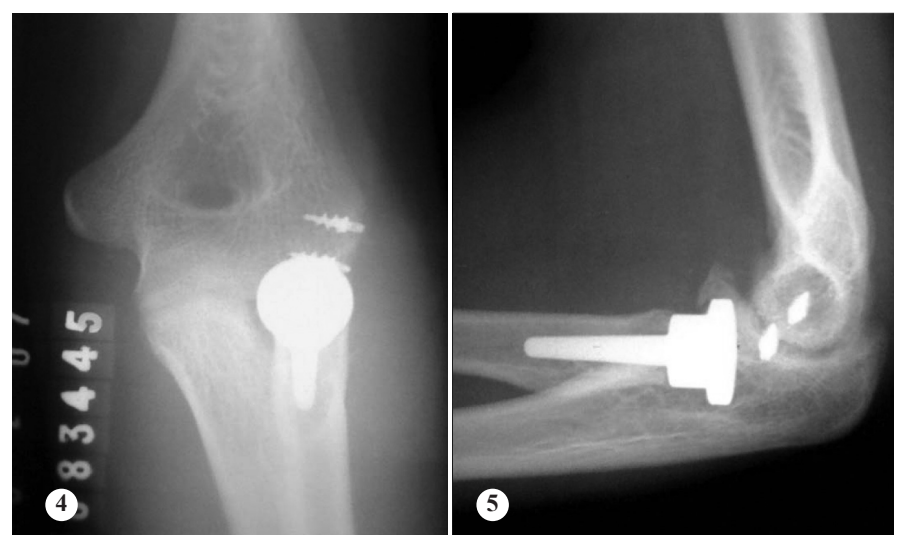

Figures 4 and $\mathbf{5}$ - Radiographs demonstrating the postoperative result, with placement of a metal prosthesis in the head of the radius and lateral ligament suturing, with anchors. 
Box 2 - Treatment instituted for fracture of the radial head, fracture of the coronoid process and injury of the ulnar nerve.

\begin{tabular}{|c|c|}
\hline \multicolumn{2}{|c|}{ Treatment for the radial head } \\
\hline Excision of the fragment & $2(11 \%)$ \\
\hline Open reduction with internal fixation & $7(37 \%)$ \\
\hline Prosthesis & $10(52 \%)$ \\
\hline Treatment for the coronoid \\
\hline Conservative & $9(49 \%)$ \\
\hline Suture & $2(11 \%)$ \\
\hline Suture with anchor & $6(30 \%)$ \\
\hline Suture + screw & $1(5 \%)$ \\
\hline Plate on the ulna & $1(5 \%)$ \\
\hline Procedure for ulnar nerve & 0 \\
\hline
\end{tabular}

Box 3 - Functional results.

\begin{tabular}{|c|c|}
\hline Mean flexion/extension & $112^{\circ}$ \\
\hline Mean pronosupination & $127.9^{\circ}$ \\
\hline Mean contracture in flexion & $24.3^{\circ}$ \\
\hline Mean maximum flexion & $131.8^{\circ}$ \\
\hline Functional ROM & $10(55 \%)$ \\
\hline Calcifications & $10(55 \%)$ \\
\hline \multicolumn{2}{|c|}{ Results from MEPS } \\
\hline Mean & $86.05(55-100)$ \\
\hline Excellent $(>89)$ & 10 \\
\hline Good $(75-89)$ & 5 \\
\hline Fair $(60-74)$ & 2 \\
\hline Poor $(<60)$ & 2 \\
\hline
\end{tabular}

was $131.8^{\circ} \pm 15^{\circ}$. In relation to pronation/supination, the final mean was $127.9^{\circ} \pm 48^{\circ}$. The functional range of motion, determined in accordance with the criteria of Morrey et $\mathrm{al}^{(8)}$ (flexion-extension of at least 30$130^{\circ}$ and pronation-supination of at least $100^{\circ}$ ), was obtained in the cases of ten patients. The mean from the MEPS questionnaire was 86 points, and this assessment produced ten excellent, five good, three fair and two poor results.

In comparing the fracture patterns of the head of the radius and the coronoid, the treatment applied, the side affected and the trauma mechanism with the clinical result (MEPS), no statistically significant correlation was found. In relation to the time elapsed until surgery, the patients who underwent operations not more than 14 days after the trauma achieved clinical results that were statistically significantly better than those of the patients operated after more than 14 days had elapsed $(p=0.039)$. There was no sta- tistically significant difference between the patients who presented a functional range of motion and those who did not, in relation to the clinical result. However, in evaluating each movement separately, the patients who achieved flexion/extension greater than $100^{\circ}$ had better results than those shown by patients with flexion/extension less than $100^{\circ}(\mathrm{p}=0.002)$. No such difference was found in assessing patients with pronation/supination greater than or less than $100^{\circ}$. In assessing flexion and extension separately, it was observed that the patients with flexion greater than $130^{\circ}$ did not obtain better results than did those with flexion less than this value. In assessing the final extension (or contracture in flexion), it was observed that the patients with contracture in flexion that was less than $30^{\circ}$ achieved results that were statistically better than did those with contracture greater than $30^{\circ}$ $(p=0.000)$ (Table 1).

Table 1 - Statistically significant data in relation to MEPS.

\begin{tabular}{c|c|c|c|c|c|c}
\hline \multirow{2}{*}{} & \multicolumn{2}{|c|}{$\begin{array}{c}\text { Time elapsed until } \\
\text { surgery }\end{array}$} & \multicolumn{2}{c|}{$\begin{array}{c}\text { Flexion/ } \\
\text { extension }\end{array}$} & \multicolumn{2}{|c}{ Final extension } \\
\cline { 2 - 7 } & $<14$ days & $>14$ days & $<100$ & $>100$ & $<30$ & $>30$ \\
\hline No. of cases & 10 & 9 & 7 & 12 & 14 & 5 \\
\hline MEPS & 93.5 & 77.78 & 70 & 95.42 & 93,57 & 65 \\
\hline$p$ value & \multicolumn{2}{|c|}{0.039} & \multicolumn{2}{c|}{0.002} & \multicolumn{2}{c}{0.000} \\
\hline
\end{tabular}

With regard to complications, one patient who initially underwent fixation of the head of the radius using a plate evolved to pseudarthrosis, and the synthesis was then converted to arthroplasty. This patient evolved well and presented MEPS of 80 points, six years after the operation. Another patient initially underwent partial resection of the head of the radius and evolved acutely with instability. Arthroplasty was performed ten days later. This case evolved poorly, with MEPS of 60 points, four years after the operation. This individual had not done the rehabilitation as prescribed. We included this patient in the arthroplasty group because of the time at which the treatment was changed. Neurological complications were more common in our sample, with three cases of peripheral neurological impairment. One patient presented neuropraxia of the ulnar and median nerves during the immediate postoperative period, but evolved with full recovery achieved around one year after the operation. 
Another patient evolved with symptoms of ulnar nerve compression, one year after the operation, presenting hypoesthesia of the ring finger and smallest finger of the affected limb. This patient is awaiting a procedure to release the ulnar nerve. Another patient presented an iatrogenic lesion on the posterior interosseous nerve during the surgery, and underwent neurorrhaphy with a graft from the sural nerve. This patient did not recover extensor muscle function and is awaiting a procedure for tendon transfer.

\section{DISCUSSION}

The terrible triad of the elbow is a severe injury that is very difficult to treat. It often evolves with loss of elbow range of motion. The most common trauma mechanism found within our setting was a fall from a height, in which the impact occurred with the elbow and hand extended. The recommended treatment is surgical, given that conservative treatment has proven to be ineffective, evolving in most cases with recurrent instability ${ }^{(3)}$.

Type 3 fractures of the coronoid are considered to be the most difficult type to treat. If done adequately, this restores elbow stability ${ }^{(9,10,11)}$. In relation to type 1 fractures, some authors have taken the view that regardless of fracture magnitude, fixation of coronoid fractures improves the clinical results, but it is unclear to what extent the diminution of elbow stability can be fully correlated with a small fracture ${ }^{(3,12)}$. Open reduction and internal fixation of coronoid fractures in the terrible triad is considered to be the most common treatment, but in this case series conservative treatment was applied to a number of patients similar to the number of surgical cases (49\%), and none of the patients had recurrent instability ${ }^{(13)}$. We believe that the stability achieved was due to appropriate selection of cases for conservative treatment, which was only applied to type 1 fractures.

The head of the radius is an important secondary stabilizer of the elbow against valgus loading and posterior translation. With the rupturing of the medial ligament complex that commonly occurs in these lesions, the head of the radius comes to have an even more important role as a stabilizer of the elbow against valgus stress ${ }^{(14)}$. Resection of this structure in patients with fracture-dislocation may lead to insta- bility and arthrosis ${ }^{(15,16)}$. Every effort should be made towards attempting to maintain the head of the radius, either through osteosynthesis or through arthroplasty, which were the methods used in $85 \%$ of the patients evaluated. Just like in the coronoid, very small fragments of the head of the radius that it was impossible to fix, and which did not interfere with the stability of the elbow, were resected $(10 \%)$ or were treated without fixation (5\%).

Reconstruction of the soft tissues is also fundamental for treating the terrible triad. In our protocol, we chose to perform systematic reconstruction of the lateral soft tissues preferentially through reinsertion using anchors (Figures 2, 3, 4 and 5). In relation to the medial collateral ligament, it is believed that maintenance of a well reduced and stable elbow promotes healing of this ligament. This was suggested by Josefsson et $\mathrm{al}^{(17)}$, who conducted a randomized prospective study among patients with simple dislocation of the elbow and observed that those who underwent surgical repair of the medial ligament complex evolved similarly to those who were treated conservatively. Forthman et $\mathrm{al}^{(18)}$ prospectively assessed patients with fracture-dislocation of the elbow and did not perform repairs on the medial collateral ligament in cases in which stability was achieved after reconstruction of the fractures and the lateral collateral. They concluded that stability and satisfactory elbow function could be restored without repairing the medial collateral ligament in most cases of fracture-dislocation. Thus, ruptures of the medial collateral ligament are the last injury to be repaired, and this is done only in cases in which the elbow remains unstable after fixation of the fractures and lateral soft tissues ${ }^{(19)}$.

Among the complications described were recurrent instability and calcifications. Even with an adequate surgical technique, instability may occur because of poor-quality bone and/or soft tissue, major comminution of the fracture or lack of cooperation from the patient after the operation. This situation is better treated by means of ligament reconstruction in association with a complementary articulated external fixator than by prolonged immobilization in flexion $^{(19)}$. If an incongruent elbow is maintained, this situation may evolve with pain, stiffness and even joint degeneration. Instability may also be manifested later on, as a consequence of this lesion, and it should 
be treated ${ }^{(1,4)}$. Heterotopic ossification and calcification in the elbow are common after treatment of the terrible triad. Pugh et $\mathrm{al}^{(12)}$ did not observe any significant difference in the rates of heterotopic ossification and synostosis between patients who were users and nonusers of indomethacin. We chose not to use prophylactic indomethacin in our orthopedics service, because the efficacy of this measure in the elbow remains unproven ${ }^{(20)}$.

The terrible triad of the elbow is a difficult-to manage injury and, even with appropriate treatment, it is only rarely possible to achieve a normal elbow after the treatment ${ }^{(21)}$. The mean range of flexion-extension of $113^{\circ}$ and the mean contracture in flexion of $24^{\circ}$ showed us that limitations on the range of motion are common findings in treating this injury. Although only slightly more than half of the patients $(55 \%)$ continued to have a functional range of motion (55\%), the final mean MEPS was 86 points, with 16 results that were excellent or good. This showed us that despite the residual deficit, the patients evolved with good clinical results. It should also be emphasized that some patients presented a range of motion that was very close to functional (patients with pronation-supination of $95^{\circ}$ and functional flexionextension, or with flexion-extension of $35-130^{\circ}$ and pronation-supination greater than $100^{\circ}$ ). Thus, these patients continued to have good elbow function for daily activities, even though they were not considered to present a functional range of motion according to the criteria adopted.

\section{CONCLUSION}

The surgical procedure should be performed within 14 days, with the aim of achieving a congruent elbow, with a range of motion greater than $100^{\circ}$ of flexion/ extension and contracture in flexion of less than $30^{\circ}$.

\section{REFERENCES}

1. O'driscoll, SW, Jupiter JB, King GJ, Hotchkiss RN, Morrey BF. The unstable elbow. J Bone Joint Surg Am. 2000; 82(5):724-38.

2. Hotchkiss RN. Fractures and dislocations of the elbow. In: Rockwood CA, Green DP, Bucholz RW, Heckman JD, editors. Rockwood and Green's fractures in adults. 4th ed. Philadelphia: Lippincott-Raven; 1996. p. 980-981.

3. Ring D, Jupiter JB, Zilberfarb J. Posterior dislocation of the elbow with fractures of the radial head and coronoid. J Bone Joint Surg Am. 2002;84-A(4):547-51.

4. Pugh DM, McKee MD. The "Terrible Triad" of the elbow. Techn Hand Upper Extrem Surg. 2002; 6(1):21-29.

5. Mason ML. Some observations on fractures of the head of the radius with a review of one hundred cases. Br J Surg. 1954;42(172):123-32.

6. Regan W, Morrey BF. Classification and treatment of coronoid process fractures. Orthopedics. 1992;15(7):845-8.

7. Lindenhovius AL, Jupiter JB, Ring D. Comparison of acute versus subacute treatment of terrible triad injuries of the elbow. J Hand Surg Am. 2008;33(6):920-6.

8. Morrey BF, An KN. Functional evaluation of the elbow. In: Morrey BF, Sanchez-Sotelo J. The elbow and its disorders. Philadelphia: Saunders/Elsevier; 2009. p.80-91.

9. Ring D, Jupiter JB, Simpson NS. Monteggia fractures in adults. J Bone Joint Surg Am. 1998;80(12):1733-44

10. Ring D, Jupiter JB, Sanders RW, Mast J, Simpson NS. Transolecranon fracturedislocation of the elbow. J Orthop Trauma. 1997;11(8):545-50.

11. Regan W, Morrey B. Fractures of the coronoid process of the ulna. J Bone Joint Surg Am. 1989;71(9):1348-54.
12. Pugh DM, Wild LM, Schemitsch EH, King GJ, McKee MD. Standard surgical protocol to treat elbow dislocations with radial head and coronoid fractures. J Bone Joint Surg Am. 2004;86(6):1122-30.

13. Ring D, Jupiter JB. Operative fixation and reconstruction of the coronoid. Tech Orthop. 2000;15(2):147-54

14. Morrey BF, Tanaka S, An KN. Valgus stability of the elbow. A definition of primary and secondary constraints. Clin Orthop Relat Res. 1991;(265):187-95.

15. Zagorski JB. Complex fractures about the elbow. Instr Course Lect. 1990;39:265-70.

16. Josefsson PO, Gentz CF, Johnell O, Wendeberg B. Dislocations of the elbow and intraarticular fractures. Clin Orthop Relat Res. 1989;(246):126-30.

17. Josefsson PO, Gentz CF, Johnell O, Wendeberg B. Surgical versus nonsurgical treatment of ligamentous injuries following dislocations of the elbow joint. Clin Orthop Relat Res. 1987;(214):165-9.

18. Forthman C, Henket M, Ring DC. Elbow dislocation with intra-articular fracture: the results of operative treatment without repair of the medial collateral ligament. J Hand Surg Am. 2007;32(8):1200-9.

19. McKee MD, Bowden SH, King GJ, Patterson SD, Jupiter JB, Bamberger HB, et al. Management of recurrent, complex instability of the elbow with a hinged external fixator. J Bone Joint Surg Br. 1998;80(6):1031-6.

20. Motta Filho GR, Malta MC. Lesões ligamentares agudas do cotovelo. Rev Bras Ortop. 2002;37(9):369-80.

21. Amis $A A$, Miller $\mathrm{JH}$. The mechanisms of elbow fractures: an investigation using impact tests in vitro. Injury. 1995;26(3):163-8. 